\title{
[gw22-e0647] EFFECT OF VALARSARTAN ON CARDIAC NOREPINEPHRINE RELEASE UNDER ISCHAEMIC CONDITION
}

Wang Yuqin 252 Hospital Of The Pla, Beijing, China

10.1136/heartjnl-2011-300867.331

The aim of this study is to investigate the effect of valarsartan in different concentration on cardiac norepinephrine (NE) release in isolated perfused guinea pig heart under ischaemic condition. Male guinea pigs hearts were excised, isolated and perfused by using the Langendorff technique. Valarsartan (1, $10100 \mathrm{n} / \mathrm{mol}$ ) was perfused respectively $10 \mathrm{~min}$ before the global ischaemic. Coronary effluent were collected and subsequently analysed for NE and dihydroxyphenylglycol (DHPG) by High-performance liquid chromatography (HPLC). In ischaemic group and valarsartan (1, $10100 \mathrm{n} / \mathrm{mol})$ group NE release was significant increased compare with control group $(\mathrm{p}<0.05)$, moreover among valarsartan $(1,10100 \mathrm{n} / \mathrm{mol})$ groups NE release was increased and showed a small but statistically significant concentration depended trend $(p<0.05)$. At the same time, the content of DHPG was significantly decreased compared with control group and showed a concentration depended trend as well ( $p<0.05$ ). This study demonstrates that valarsratan can not only promote NE release but also show a concentration-dependent trend on NE releasing under ischaemic conditions. This study discovered that valarsartan can evoke NE release and show a concentration depended trend under short time ischaemic (guinea pig isolated heart $10 \mathrm{~min}$ ) condition. 